OPEN ACCESS

Edited by:

Amadeu K. Sum,

Colorado School of Mines,

United States

Reviewed by:

Jiafei Zhao,

Dalian University of Technology, China

Alejandro Gil-Villegas,

University of Guanajuato, Mexico

${ }^{*}$ Correspondence:

Tsutomu Uchida

t-uchida@eng.hokudai.ac.jp

Specialty section

This article was submitted to Physical Chemistry and Chemical

Physics,

a section of the journa

Frontiers in Chemistry

Received: 26 March 2020

Accepted: 08 May 2020

Published: 05 June 2020

Citation:

Uchida T, Miyoshi H, Sugibuchi R,

Suzuta A, Yamazaki K and Gohara K

(2020) Contribution of Ultra-Fine

Bubbles to Promoting Effect on

Propane Hydrate Formation.

Front. Chem. 8:480

doi: $10.3389 /$ fchem.2020.00480

\section{Contribution of Ultra-Fine Bubbles to Promoting Effect on Propane Hydrate Formation}

\author{
Tsutomu Uchida ${ }^{1 *}$, Hiroshi Miyoshi ${ }^{2}$, Ren Sugibuchi ${ }^{2}$, Akio Suzuta $^{2}$, Kenji Yamazaki $^{1}$ and \\ Kazutoshi Gohara ${ }^{1}$
}

${ }^{1}$ Faculty of Engineering, Hokkaido University, Sapporo, Japan, ${ }^{2}$ Graduate School of Engineering, Hokkaido University, Sapporo, Japan

To investigate experimentally how ultra-fine bubbles (UFBs) may promote hydrate formation, we examined the formation of propane $\left(\mathrm{C}_{3} \mathrm{H}_{8}\right)$ hydrate from UFB-infused water solution using two preparation methods. In one method, we used $\mathrm{C}_{3} \mathrm{H}_{8}$-hydrate dissociated water, and in the other, $\mathrm{C}_{3} \mathrm{H}_{8}$-UFB-included water prepared with a generator. In both solutions, the initial conditions had a UFB number density of up to $10^{9} \mathrm{~mL}^{-1}$. This number density decreased by only about a half when stored at room temperature for 2 days, indicating that enough amount of UFBs were stably present at least during the formation experiments. Compared to the case without UFBs, the nucleation probabilities within $50 \mathrm{~h}$ were $\sim 1.3$ times higher with the UFBs, and the induction times, the time period required for the bulk hydrate formation, were significantly shortened. These results confirmed that UFB-containing water promotes $\mathrm{C}_{3} \mathrm{H}_{8}$-hydrate formation. Combined with the UFB-stability experiments, we conclude that a high number density of UFBs in water contributes to the hydrate promoting effect. Also, consistent with previous research, the present study on $\mathrm{C}_{3} \mathrm{H}_{8}$ hydrates showed that the promoting effect would occur even in water that had not experienced any hydrate structures. Applying these findings to the debate over the promoting (or "memory") effect of gas hydrates, we argue that the gas dissolution hypothesis is the more likely explanation for the effect.

Keywords: nanobubble, stability, number density, memory effect, propane, induction time

\section{INTRODUCTION}

Gas hydrates that exist below the deep sea floor are both an unconventional natural gas resource and a potential source of greenhouse gas. In addition, gas-hydrate formation can be a nuisance when it starts to plug gas pipelines in cold regions. Such interests have stimulated much research and development on gas hydrates (Kvenvolden, 1988; Sloan, 2004; Sloan and Koh, 2007; Masuda et al., 2016). For example, with the gas pipeline issue, research has focused on suppressing the formation and growth of gas hydrate. However, as the hydrate form contains gas at relatively high density, gas hydrate is regarded as a promising medium for transporting and storing the gas (Gudmundsson and Borrehaug, 1996; Ida and Kohda, 2004; Horiguchi et al., 2011; Mimachi et al., 2014; Takeya et al., 2018). 
Gas hydrate is formed by a reaction between water and the guest gas at low temperatures and high pressures. But the nucleation of gas-hydrate crystals requires a relatively large supercooling (or super-saturation). Such conditions necessitate additional energy for gas-hydrate formation and make it difficult to control the formation process. Thus, a key research goal is to find more efficient ways to form gas hydrates.

Propane $\left(\mathrm{C}_{3} \mathrm{H}_{8}\right)$ is the main component of LPG and a component of natural gas. Its solubility in water (about $2.7 \times$ $10^{-5}$ in mole fraction at $293.2 \mathrm{~K}$; (The Chemical Society of Japan, 2004) $)$ is similar to methane $\left(\mathrm{CH}_{4}\right)$. The formation of $\mathrm{C}_{3} \mathrm{H}_{8}$ hydrate via the reaction between $\mathrm{C}_{3} \mathrm{H}_{8}$ gas and pure water is difficult (Christiansen and Sloan, 1994; Giavarini et al., 2003). This difficulty has been understood as a consequence of the labile-cluster nucleation hypothesis, in particular, a difficulty in forming hexakaidecahedral $\left(5^{12} 6^{4}\right)$ cavities (Christiansen and Sloan, 1994).

At present, the "memory effect" is the most promising way to increase the efficiency of forming gas hydrate (Ripmeester and Alavi, 2016). Another way to promote $\mathrm{C}_{3} \mathrm{H}_{8}$-hydrate formation is by using "ice-melting water," which is water from just-melted ice Giavarini et al. (2003). Ida and Kohda (2004) investigated several such methods, arguing that the micro-bubble method was the most promising way. The mechanism by which this method works was argued to be the increase of gas-liquid interface. Zeng et al. (2006) confirmed the memory effect of $\mathrm{C}_{3} \mathrm{H}_{8}$ hydrate when they used the $\mathrm{C}_{3} \mathrm{H}_{8}$-hydrate melt water although they aimed to investigate the inhibition effect of anti-freeze proteins on the $\mathrm{C}_{3} \mathrm{H}_{8}$-hydrate formation.

The memory effect is a phenomenon in which once a formed crystal is dissociated into gas and water, and then reformed, the crystallization occurs with lower supercooling or supersaturation than when the crystal was initially formed. The mechanism is still under debate, and several hypotheses have been proposed. One hypothesis is the "water structuring hypothesis" that the fragments of hydrate-lattice structure remains in the dissociated water (Hwang et al., 1990; Parent and Bishnoi, 1996; Ohmura et al., 2003; Buchanan et al., 2005; Sloan and Koh, 2007; Sefidroodi et al., 2013). This is consistent with the concept that water has a dynamic structure, so it is considered to be a promising hypothesis. However, the existence of such "fragments" has not been established.

Another hypothesis is the "gas dissolution hypothesis" that comes from the requirement of a sufficient concentration of guest molecules in the liquid phase for hydrate to form (Rodger, 2000). Most guest molecules are hydrophobic, with relatively low solubility in water. In the crystalline gas hydrate, the gas concentration is hundreds of times its solubility in water, thus when the hydrate grows, a large amount of guest molecules must be supplied from the gas phase. For example, the mole fraction of $\mathrm{C}_{3} \mathrm{H}_{8}$ over $\mathrm{H}_{2} \mathrm{O}$ in the hydrate structure is estimated to be about two thousand times that of the $\mathrm{C}_{3} \mathrm{H}_{8}$ solubility in water. This difficulty of acquiring enough guest molecules is considered to be

Abbreviations: UFB, ultra-fine bubble (sub-micron sized); FFT, freeze-fractured replica observation via transmission electron microscope; LS, laser-light scattering; PTA, particle tracking analysis. a major barrier to crystallization. Uchida et al. (2016a,b); Uchida et al. $(2017,2020)$ demonstrated experimentally the presence of ultra-fine bubbles (UFBs) in hydrate-dissociated water. They argued that the UFBs are a source of guest molecules to the liquid phase, and they suggested that these UFBs produce the memory effect via the gas dissolution hypothesis.

UFBs are small gas bubbles <1 $\mu \mathrm{m}$ (ISO 20408-1:2017, 2017). They have unique properties such as low buoyancy, high internal pressure, and a low rate of coalescence due to repulsive forces from their negative surface charges ( $\zeta$-potential) (Takahashi, 2005; Seddon et al., 2012; Oshita and Uchida, 2013). These properties allow UFBs to remain in the liquid for a long time. Usually, UFB-containing water is prepared with a fine-bubble generator. Our previous studies (Uchida et al., 2016a,b, 2017, 2020) have confirmed that gas hydrate dissociation produces a high concentration of UFBs in water. This phenomenon is also supported by molecular dynamic simulations (Yagasaki et al., 2014; Bagherzadeh et al., 2015).

The relationship between UFBs and the memory effect has been studied using $\mathrm{CH}_{4}$, ethane $\left(\mathrm{C}_{2} \mathrm{H}_{6}\right)$, and carbon dioxide $\left(\mathrm{CO}_{2}\right)$ hydrates (Uchida et al., 2016a,b, 2017, 2020). All of these hydrates have the same sI (structure-I) hydrate. Here we ask whether the UFBs have the same role in the memory effect of the sII (structure-II) hydrate by studying the effect experimentally using $\mathrm{C}_{3} \mathrm{H}_{8}$ gas. As UFBs used in the present study were much smaller than micro bubbles, our approach differs from the microbubble method proposed by Ida and Kohda (2004). Therefore, we also investigated the stability of $\mathrm{C}_{3} \mathrm{H}_{8}$-UFBs by their number density change with storage time at room temperature.

\section{EXPERIMENTAL METHODS}

\section{Materials and UFB Measurements}

As in our previous studies (Uchida et al., 2016b, 2020), three liquid samples were used for the experiments: pure water, $\mathrm{C}_{3} \mathrm{H}_{8}$ hydrate dissociated water, and $\mathrm{C}_{3} \mathrm{H}_{8}$-UFB-included water. Pure water here means ion-exchanged distilled water of resistivity about $15 \mathrm{M} \Omega \mathrm{cm}$. The $\mathrm{C}_{3} \mathrm{H}_{8}$-hydrate dissociated water was prepared by dissolving about $2.5 \mathrm{~g}$ of $\mathrm{C}_{3} \mathrm{H}_{8}$-hydrate crystal in about $50 \mathrm{~mL}$ of pure water at about $293 \mathrm{~K}$. The source crystal for this sample was retrieved from our reaction vessel at about $200 \mathrm{~K}$. The $\mathrm{C}_{3} \mathrm{H}_{8}$-UFB-included water was prepared with a micro-bubble generator (Aura Tec, Fukuoka, Japan, type OM4MDG-045) by supplying $\mathrm{C}_{3} \mathrm{H}_{8}$ gas (99\% in purity, Hokkaido Air Water, Hokkaido, Japan) at $0.25 \mathrm{MPa}$ into $1 \mathrm{~L}$ of pure water maintained at $293 \mathrm{~K}$ by immersing the water-filled beaker into the temperature-controlled bath (Otsuka Electronics, Osaka, Japan, type NM-454L). To obtain sufficient UFBs, the circulating time was set for $1 \mathrm{~h}$. These liquids were used for the $\mathrm{C}_{3} \mathrm{H}_{8}$-hydrate formation test more than $1 \mathrm{~h}$ after the complete disappearance of micro- or macroscopic bubbles. The $\mathrm{pH}$ value was measured with a pH sensor (Sato Keiryoki, Tokyo, Japan, type SK-620PHII).

The number and size distributions of UFBs in the solution were measured by both laser-light scattering (LS) and by freeze-fractured replica observation via transmission electron microscope (FFT). In the LS technique, an Ar-ion laser (Omnichrome, CA, USA, type 543-150 GS, $\lambda=514.5 \mathrm{~nm}, 5$ 
$\mathrm{mW}$ ) light was introduced into an optical glass cell (Toshinriko, Tokyo, Japan, type PSK-3: about $1 \mathrm{~cm}^{3}$ ) in which each liquid sample had been dispensed. The 90 -degree light scattering image was recorded by CCD camera (Watec, Yamagata, Japan, type WAT-232S) from which we counted the bright spots in a unit volume (using Image J software). The average number density was estimated from 16 images for each sample. Preliminary experiments have confirmed that this method can measure UFBs with a diameter of larger than $300 \mathrm{~nm}$ and with the number density more than $10^{6} \mathrm{~mL}^{-1}$ (Uchida et al., 2020).

The FFT method we used is described in detail in Uchida et al. (2016a,b,c); Uchida et al. (2020), so we describe it only briefly here. A small amount $(<10 \mu \mathrm{L})$ of liquid sample was quickly frozen by immersing it into liquid nitrogen. The frozen sample was then set in the replication system (JEOL, Tokyo, Japan, type JFD-9010) and fractured under low temperature (about $150 \mathrm{~K})$ and high vacuum $\left(<10^{-4} \mathrm{~Pa}\right)$ conditions to form a freshly fractured surface. On this surface, both platinum and carbon were deposited to form a thin film that replicates the roughness of the fractured surface. After transferring to a $\mathrm{Cu}$-grid having $43 \mu \mathrm{m} \times 43 \mu \mathrm{m}$ opening, we observed the fractured surface using a high-resolution transmission electron microscope (TEM: JEOL, JEM-2010, at $200 \mathrm{kV}$ accelerating voltage). An imaging plate (Fujifilm, Tokyo, Japan, type FDL-UR-V) was used for acquiring the observed image. This method allows us to observe UFBs, and distinguish them from impurities (the former is a hemispherical hollow, the latter sticks up). To obtain the average value of the UFB distribution, we measured at least three independent replica-film samples for a specified liquid sample.

To overcome the limitation of the FFT measurement and to cover the wider size-ranged UFBs, we combine another measurement method. For observing the smaller UFBs, we used the commercially available particle tracking analysis (PTA) method (Quantum Design Japan, Tokyo, Japan, type NS500, $\lambda$ $=635 \mathrm{~nm}$ ). This system allowed us to obtain the particle size distributions and the average number density of UFBs having diameters of about 20-300 nm. The averaged values for the UFB distribution were estimated from at least six measurements for a specified liquid sample.

With the above methods, we measured the size and density of UFBs immediately after preparing the samples by storing the liquid sample in glass bottles (about $6.5 \mathrm{~mL}$, without head space) at room temperature. The average number densities were measured by LS and PTA methods for 2 days. As mentioned in our previous studies (Uchida et al., 2016a,b,c), the number density measured by the FFT method would be affected by the quenching process. Thus, we avoid the quantitative comparison between results obtained by different methods in the present study.

\section{$\mathrm{C}_{3} \mathrm{H}_{8}$-hydrate Formation and Evaluation of Promoting Effects}

We used the same system as that in our previous study (Uchida et al., 2016a, 2020) for the $\mathrm{C}_{3} \mathrm{H}_{8}$-hydrate formation tests. Briefly, about $50 \mathrm{~cm}^{3}$ of liquid sample was set in a batch-type reaction vessel (inner volume: $232.2 \mathrm{~cm}^{3}$ ). To reduce formation of surface nanobubbles on the reaction vessel wall after introducing the liquid sample, the UFB-containing water was stored at room temperature for at least $1 \mathrm{~h}$ prior to its use in the experiments. The sample was free of visible bubbles. After the purge process, $\mathrm{C}_{3} \mathrm{H}_{8}$ gas was pressurized at a set value (about $0.45 \mathrm{MPa}$ ). The temperature of the vessel containing the sample was controlled by immersing in a cooling bath set at $273.9 \pm 0.4 \mathrm{~K}$. The $\mathrm{C}_{3} \mathrm{H}_{8^{-}}$ hydrate formation tests were started with a gentle agitation of about $300 \mathrm{rpm}$.

The promoting effect is defined as the decrease in length of the induction time of gas hydrate formation $\Delta t$ compared to the control condition (with pure water in the present study). The induction time is the time from when the temperature in the vessel reaches the equilibrium value to the time when the temperature of the vessel increases suddenly due to the exothermic process of hydrate formation. The latter time is also recognized by the sudden pressure drop due to the consumption of $\mathrm{C}_{3} \mathrm{H}_{8}$ gas. If the hydrate did not form by $50 \mathrm{~h}$, we stopped the experiment and defined it "not formed." As the nucleation process of gas hydrate is known to be stochastic, we evaluate the probability nucleation rate $P(t)$ from 11 repeated experiments. The curve fitting was done by OriginPro (OriginLab, ver. 9.0J). The strength of the promoting effect $<\Delta t_{\text {ind }}>$ is defined as the integration over time of $P_{U F B}(t)-P_{p w}(t)$, where $P_{U F B}(t)$ is the rate for the UFB-containing water, $P_{p w}(t)$ that for pure water.

For the statistical analysis, we estimate the significance using the Tukey-Kramer test (MS Excel 2010 and BellCurve) for at least $95 \%$ confidence $(p<0.05)$.

\section{RESULTS AND DISCUSSION \\ Distribution of UFBs in $\mathrm{C}_{3} \mathrm{H}_{8}$-hydrate Dissociated Water}

Some of the liquid sample used for the hydrate-formation experiment was set aside for analyzing its size distribution of UFBs by the LS method, the PTA method, and the FFT method. Figure 1 shows typical TEM images of $\mathrm{C}_{3} \mathrm{H}_{8}$ UFBs in the $\mathrm{C}_{3} \mathrm{H}_{8}$-hydrate dissociated water obtained by the FFT method. Consistent with this image, we found that most UFBs are spherical or oval, and that their size distributions had similarities to those observed in other hydrocarbon-gas UFBs (Uchida et al., 2016a,b).

We calculated the average particle size $D$ and the number density $N$ of $\mathrm{C}_{3} \mathrm{H}_{8}$ UFBs in each liquid sample. These quantities were calculated within $1 \mathrm{~h}$ of sample preparation and 1 day later. For example, results in Table 1 show for the LS measurements that UFBs over $300 \mathrm{~nm}$ in diameter had a number density of $10.7( \pm 4.2) \times 10^{8} \mathrm{~mL}^{-1}$ in the $\mathrm{C}_{3} \mathrm{H}_{8}$-hydrate dissociated water, but had the slightly lower concentration of $8.1( \pm 2.7)$ $\times 10^{8} \mathrm{~mL}^{-1}$ in the $\mathrm{C}_{3} \mathrm{H}_{8}$-UFB-included water. These values are considered to be appropriate by the comparison to those obtained by the PTA method, although they are smaller than those obtained by other methods. Overall, there is little difference in number density between the UFB-included and the hydratedissociated samples. Thus, the $\mathrm{C}_{3} \mathrm{H}_{8}$ UFBs generated by the hydrate dissociation appear to roughly stabilize at the same 

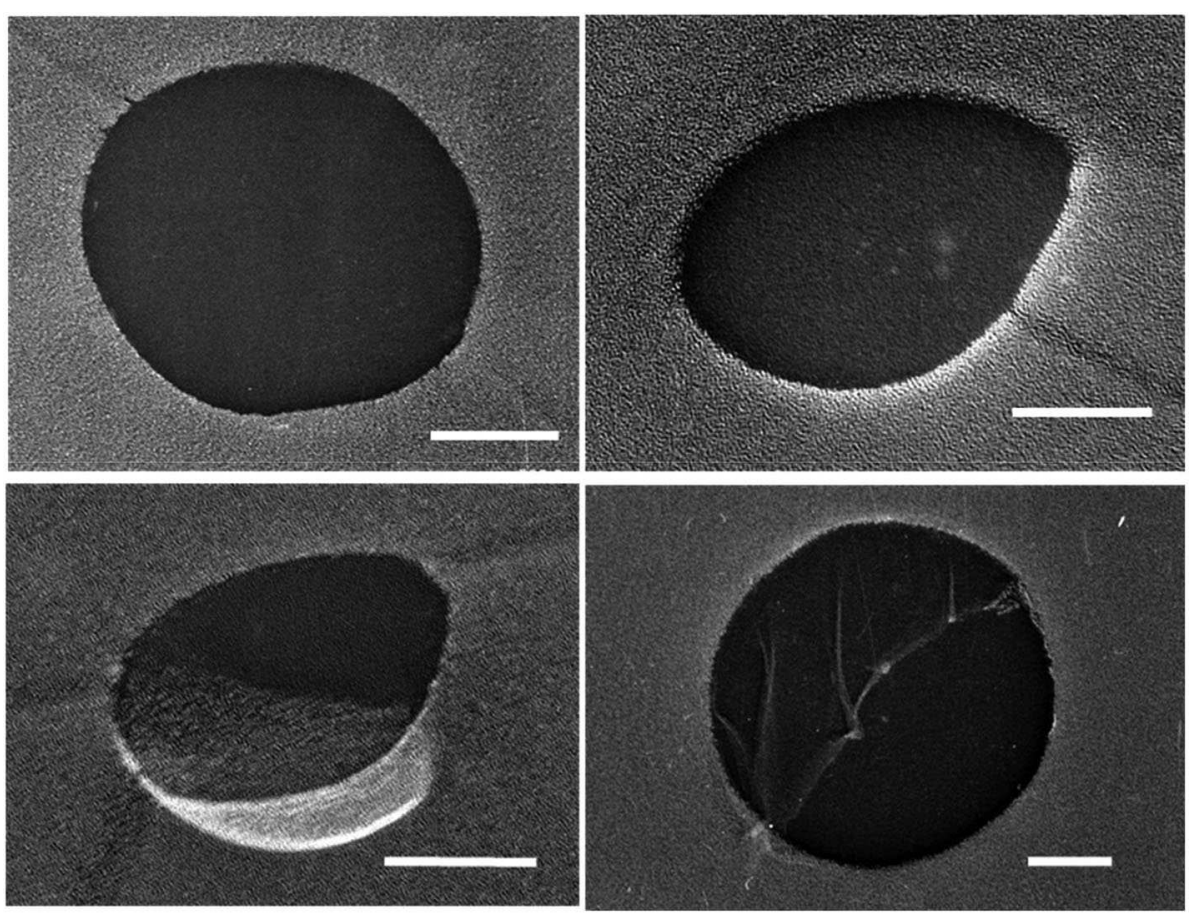

FIGURE 1 | Typical TEM images of UFBs in $\mathrm{C}_{3} \mathrm{H}_{8}$-hydrate dissociation water by the freeze-fracture replica (FFT) method. Scale bars show $100 \mathrm{~nm}$.

TABLE 1 | Average diameter $D$ and number density $N$ of UFBs in samples measured by LS, PTA, and FFT methods.

\begin{tabular}{|c|c|c|}
\hline & $D[\mathrm{~nm}]$ & $N\left[\times 10^{8} \mathrm{~mL}^{-1}\right]$ \\
\hline $\begin{array}{l}\mathrm{C}_{3} \mathrm{H}_{8} \text {-UFB-included } \\
\text { water }\end{array}$ & $\begin{array}{c}>300(\mathrm{LS}) \\
100 \pm 20 \rightarrow 124 \pm 28(\text { PTA })\end{array}$ & $\begin{array}{c}8.1 \pm 2.7 \rightarrow 6.5 \pm 2.6 \text { (LS) } \\
0.77 \pm 0.07 \rightarrow 0.55 \pm \\
0.11(\mathrm{PTA})\end{array}$ \\
\hline $\begin{array}{l}\mathrm{C}_{3} \mathrm{H}_{8} \text {-hydrate } \\
\text { dissociated water }\end{array}$ & $\begin{array}{c}385 \pm 283 \rightarrow 746 \pm \\
401(\mathrm{FFT})^{\star} \\
>300(\mathrm{LS}) \\
133 \pm 11 \rightarrow 141 \pm 14(\mathrm{PTA}) \\
\mathrm{pH}: 6.7\end{array}$ & $\begin{array}{c}6.4 \pm 2.1 \rightarrow 7.4 \pm 3.2(\mathrm{FFT}) \\
10.7 \pm 4.2 \rightarrow 6.8 \pm 4.1(\mathrm{LS}) \\
2.1 \pm 1.3 \rightarrow 1.7 \pm \\
0.8(\mathrm{PTA})^{*}\end{array}$ \\
\hline Pure water & N.A. & N.A. \\
\hline
\end{tabular}

Arrows show the change between the value within $1 \mathrm{~h}$ of sample preparation and that after about $24 \mathrm{~h}$ at room temperature. Asterisks mark those with a significant difference ( $p$ $<0.05)$. N.A. means that sufficient number of UFBs were not measured in liquid samples.

number density as that prepared by the UFB generator. N.A. in Table 1 means that sufficient number of UFBs were not measured in liquid pure water.

This conclusion is consistent with findings from other hydrocarbon-gas hydrates $\left(\mathrm{CH}_{4}\right.$ : Uchida et al., 2016a; $\mathrm{C}_{2} \mathrm{H}_{6}$ : Uchida et al., 2016b), although the number densities are larger than those from $\mathrm{CO}_{2}$-hydrate dissociated water (Uchida et al., 2020). In our previous study (Uchida et al., 2016c, 2020), we suggested that the UFB density might respond to the solubility and $\mathrm{pH}$. Thus, we expect such similarity with other hydrocarbons because the solubility of $\mathrm{C}_{3} \mathrm{H}_{8}$ gas in water is similar to that of
$\mathrm{CH}_{4}$ and because the $\mathrm{pH}$ value of the dissociated water is around seven (Table 1). In addition, the higher number density of UFBs in this case compared to the $\mathrm{CO}_{2}$-hydrate case is consistent with the higher $\mathrm{pH}$ conditions (Uchida et al., 2020).

Figure 2 shows how the number densities decreased with time over 2 days. The values are normalized by the initial number density (averaged data, within $1 \mathrm{~h}$ of generation). Each error bar shows the standard deviation. The relatively large UFBs (larger than $300 \mathrm{~nm}$ ) in the $\mathrm{C}_{3} \mathrm{H}_{8}$-hydrate dissociated water decrease in proportion to the storage time (Figure 2A), decreasing over $50 \%$ after $50 \mathrm{~h}$. In contrast, these larger UFBs in the UFB-included water decrease initially by about $10 \%$, within a few hours of generation, but then decreased much more slowly, decreasing another $10 \%$ over $50 \mathrm{~h}$. Thus, after $50 \mathrm{~h}$, the residual ratio is about 0.8 , about twice that of the $\mathrm{C}_{3} \mathrm{H}_{8}$-hydrate dissociated water. Assuming a linear decrease with time, the decrease rates of UFBs in the UFB-included water and in the $\mathrm{C}_{3} \mathrm{H}_{8}$-hydrate dissociated water are about $-0.08 \times$ $10^{6} \mathrm{~mL}^{-1} \mathrm{~h}^{-1}$ and $-1.33 \times 10^{6} \mathrm{~mL}^{-1} \mathrm{~h}^{-1}$, respectively. That is, the difference in the decrease rates is over an order of magnitude.

For the smaller UFBs, the number densities decrease as shown in Figure 2B. Despite the initial number densities differing significantly (Table 1), the residual ratios of UFBs around $100 \mathrm{~nm}$ in diameter are nearly equal after about $50 \mathrm{~h}$. Specifically, their linear rates of decrease are about $-0.50 \times 10^{6} \mathrm{~mL}^{-1} \mathrm{~h}^{-1}$ for the UFB-included samples and $-0.62 \times 10^{6} \mathrm{~mL}^{-1} \mathrm{~h}^{-1}$ for the hydrate-dissociated samples. Therefore, for both the larger and smaller UFBs, the number in the hydrate-dissociated water tends 


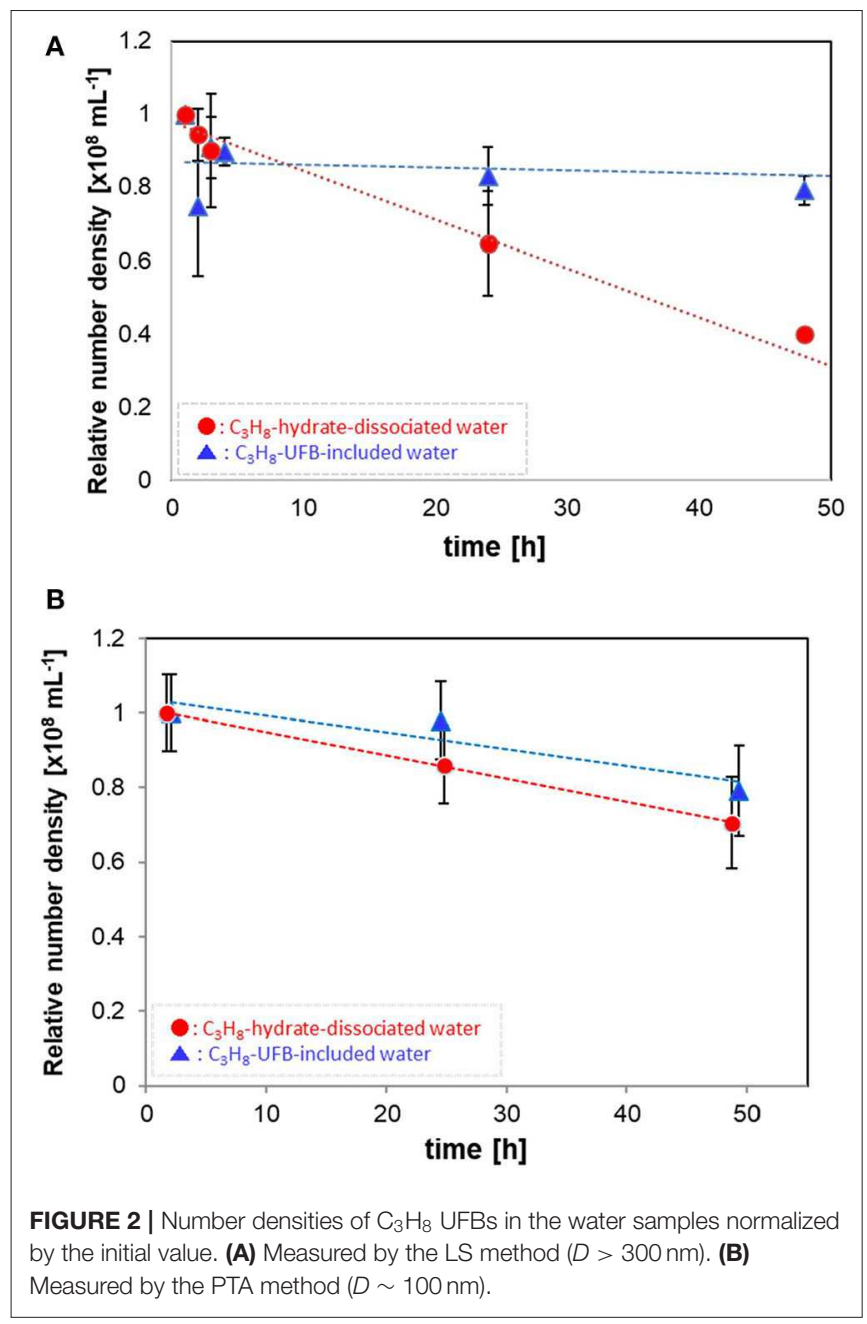

to decrease faster than that in the UFB-included water, at least over the size range observed here.

The size distribution of UFBs also changed with time. To observe the size distribution of UFBs in wider range, we must combine the different measurement methods here. As shown in Figure 3, the FFT measurement covers the larger UFBs whereas the PTA measurement covers smaller ones which slightly overlaps at the range about $100 \mathrm{~nm}$. The FFT measurements of larger UFBs in the hydrate-dissociated samples in Figure 3A shows that the distribution shifts to larger sizes over time. Similarly, the size distribution from the PTA measurements show a shift to larger sizes (Figure 3B). This shift is small, and arises from a preferential decrease in the UFBs smaller than $100 \mathrm{~nm}$. These data suggest that the initial distribution has a large distribution of sizes, from several tens of nanometers to several micrometers, but that after 1 day or more, the average value increases due to the disappearance of small UFBs or the growth of UFBs into micro-bubbles. These trends in average diameter and number density suggest Ostwald ripening, in which small UFBs dissolved and large UFBs grew, with the largest UFBs disappearing during the storage period due to their increase in
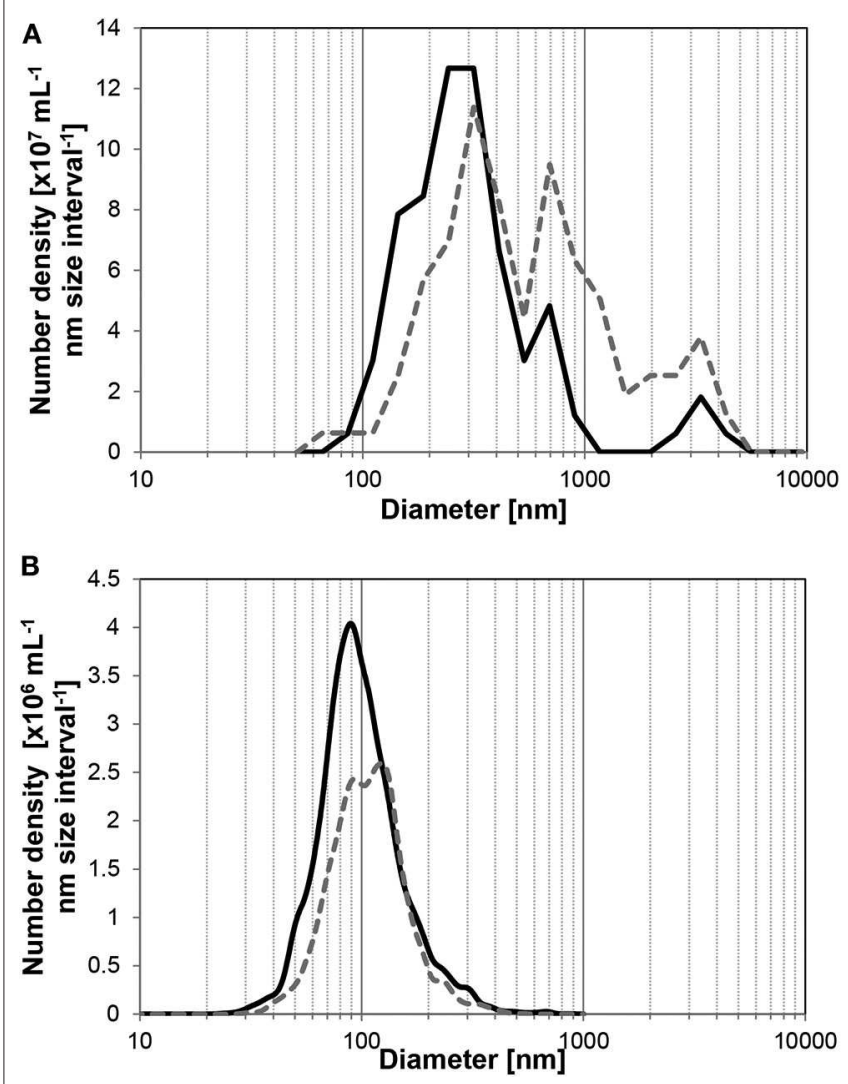

FIGURE 3 | Average size distributions of UFBs in $\mathrm{C}_{3} \mathrm{H}_{8}$-hydrate dissociated water. Solid line is the initial distribution, dashed line is that after 1 day. (A) By FFT observations $(n>4)$. (B) By PTA measurements $(n>6)$.

buoyancy. But regardless of these processes, the number density remained of order $10^{8} \mathrm{~mL}^{-1}$ in the $\mathrm{C}_{3} \mathrm{H}_{8}$-hydrate dissociated water during a 2-day storage period.

For the larger UFBs (over $300 \mathrm{~nm}$ diameter), the difference in lifespans (residual ratio) between that in the UFB-included water and that in the $\mathrm{C}_{3} \mathrm{H}_{8}$-hydrate dissociated water is likely due to the difference in the UFB-generation methods. As the UFB-included water was prepared with 1-h aeration during the UFB generation, the $\mathrm{C}_{3} \mathrm{H}_{8}$ concentration in the water should be sufficiently saturated. However, the $\mathrm{C}_{3} \mathrm{H}_{8}$-hydrate dissociated water is prepared by dissolving several crystalline pieces in pure water. Thus, the solution might not initially be saturated. UFBs are stable in water supersaturated with the source gas (Uchida et al., 2016c). Therefore, the residual ratio of UFBs in the $\mathrm{C}_{3} \mathrm{H}_{8}$-hydrate dissociated water would be lower than in $\mathrm{C}_{3} \mathrm{H}_{8}$ UFB-included water because most of the UFBs initially formed during hydrate dissociation soon dissolve into the water. UFBs larger than $300 \mathrm{~nm}$ tend to dissolve preferentially in the smaller supersaturated solution (e.g., in $\mathrm{C}_{3} \mathrm{H}_{8}$-hydrate dissociated water), whereas UFBs smaller than $100 \mathrm{~nm}$ preferentially dissolve in the sufficiently supersaturated solution (e.g., in $\mathrm{C}_{3} \mathrm{H}_{8}$-UFB included water). 


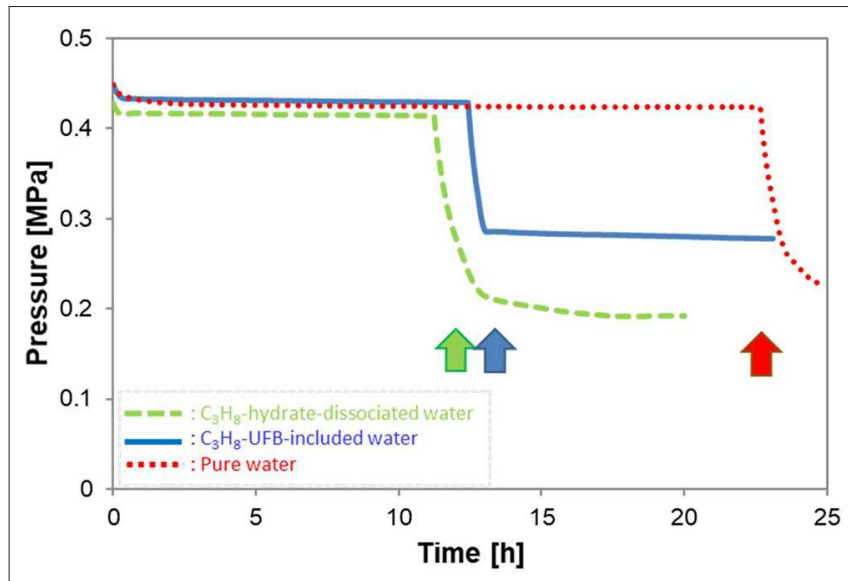

FIGURE 4 | Typical pressure profiles during hydrate formation with three kinds of solutions. Arrows show the hydrate formation point, giving the induction time.

The total number density of $\mathrm{C}_{3} \mathrm{H}_{8}$ UFBs in the solution in which $\mathrm{C}_{3} \mathrm{H}_{8}$ hydrate has just dissociated is estimated to be of order $10^{9} \sim 10^{10} \mathrm{~mL}^{-1}$. So, the use of $\mathrm{C}_{3} \mathrm{H}_{8}$-hydrate dissociated water, as done in other memory-effect experiments (such as (Zeng et al., 2006)), should have a sufficient initial supply of $\mathrm{C}_{3} \mathrm{H}_{8}$. The lifespan of UFBs in such dissociated water should be as long as that observed in the UFB-included water prepared by the UFB generator.

\section{Induction Time Measurements of $\mathrm{C}_{3} \mathrm{H}_{8}$ Hydrates}

Figure 4 shows typical pressure profiles in the vessel with formation of $\mathrm{C}_{3} \mathrm{H}_{8}$ hydrate under the conditions of $P=0.45$ $\mathrm{MPa}$ and $T=273.9 \mathrm{~K}$. All three types of liquid samples are shown. After $\mathrm{C}_{3} \mathrm{H}_{8}$ gas was introduced into the vessel, its pressure decreased slightly due to the temperature drop from room temperature. In the figure, time zero is when the temperature and pressure of the vessel reached the equilibrium ones (about $278 \mathrm{~K}$ at $0.45 \mathrm{MPa}$ ). Thus, the subsequent pressure drop indicates $\mathrm{C}_{3} \mathrm{H}_{8}$-hydrate formation (shown by arrows), so the time of this sudden drop in pressure is the induction time. Simultaneously with the pressure drop, the temperature rose. But of every 8 experiments with hydrate formation, about 3 others did not produce hydrate within $50 \mathrm{~h}$. When the latter occurred, we counted it as "non-generation."

Instead of the tens of minutes induction time of other gas hydrates $\left(\mathrm{C}_{2} \mathrm{H}_{6}\right.$ hydrate: (Uchida et al., 2016b) and $\mathrm{CO}_{2}$ hydrate: (Uchida et al., 2020)), the $\mathrm{C}_{3} \mathrm{H}_{8}$-hydrate formation required tens of hours (Figure 4). The longer induction time indicates that $\mathrm{C}_{3} \mathrm{H}_{8}$ hydrate has a larger energy barrier for crystal formation than other gas hydrates. As a consequence, the promoting effect for $\mathrm{C}_{3} \mathrm{H}_{8}$ hydrate has greater importance for controlling the hydrate-formation processes. Figure 4 also shows induction times are nearly halved in the $\mathrm{C}_{3} \mathrm{H}_{8}$-hydrate dissociated water and $\mathrm{C}_{3} \mathrm{H}_{8}$-UFB-included water over that in pure water. This result shows a strong promoting effect from using $\mathrm{C}_{3} \mathrm{H}_{8}$ UFBs.

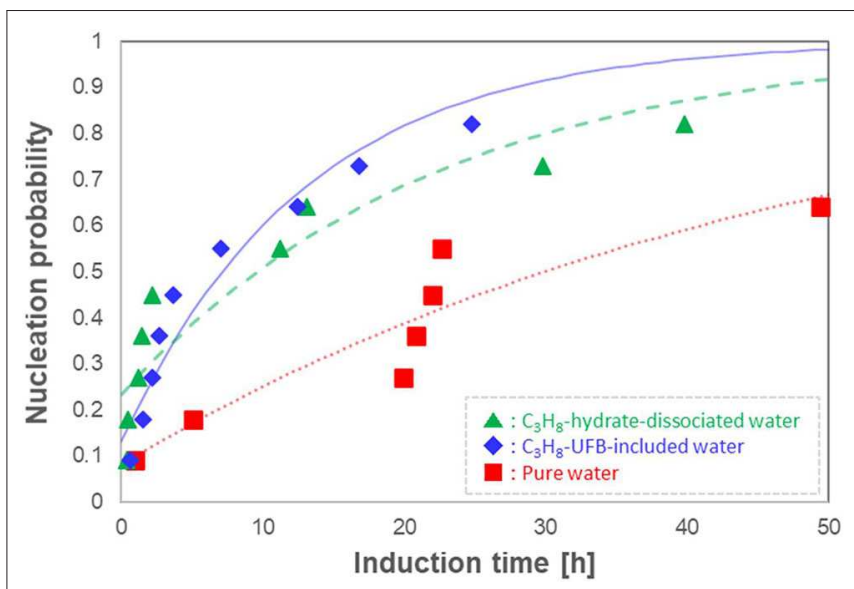

FIGURE 5 | Nucleation probability of $\mathrm{C}_{3} \mathrm{H}_{8}$ hydrate vs. induction time $(n=11)$. Each curve is a fit from Equation (1).

Given the stochastic behavior of crystal formation, we repeated the induction-time measurements 11 times under the same conditions, determining the probability distributions as done in Sowa and Maeda (2015). We show the resulting induction time series in Figure $\mathbf{5}$ as probability nucleation rate curves. This figure shows that both nucleation rate curves of the $\mathrm{C}_{3} \mathrm{H}_{8}$-hydrate dissociated water $(\boldsymbol{\Delta})$ and of the $\mathrm{C}_{3} \mathrm{H}_{8}$-UFBincluded water $(\downarrow)$ are shifted to shorter induction times than that of pure water $(\square)$. Thus, both types of liquid samples containing $\mathrm{C}_{3} \mathrm{H}_{8}$ UFBs exhibit a promoting effect and follow nearly identical curves. In addition, the formation probability within $50 \mathrm{~h}$ was 0.8 in both $\mathrm{C}_{3} \mathrm{H}_{8}$-UFB containing solutions, about 1.3 times that found for pure water.

Concerning the relatively long induction times of $\mathrm{C}_{3} \mathrm{H}_{8}$ hydrate, the difficulty of formation had been explained by the labile-cluster nucleation hypothesis and assumed that it was in the "difficulty of producing $5^{12} 6^{4}$ cavities" (Christiansen and Sloan, 1994; Sloan and Koh, 2007). Thus, if the memory effect of $\mathrm{C}_{3} \mathrm{H}_{8}$ hydrate is explained using the water structuring theory, the induction time with $\mathrm{C}_{3} \mathrm{H}_{8}$-hydrate dissociated water should be significantly shorter than that with UFB-included water, as the latter has not experienced any hydrate structure. However, the results show that both samples exhibit a similar promoting effect. We conclude that the presence of UFBs, which is a common feature of both aqueous solutions, had a dominant effect on the exhibition of the memory effect of $\mathrm{C}_{3} \mathrm{H}_{8}$ hydrate. Thus, as we found earlier (Uchida et al., 2016a,b, 2020), this conclusion supports the guest dissolution hypothesis for the memory effect on $\mathrm{C}_{3} \mathrm{H}_{8}$ hydrates, not the water structuring hypothesis.

We now analyze the promoting effect of $\mathrm{C}_{3} \mathrm{H}_{8}$ hydrate more quantitatively. To compare the fitting parameters with those obtained in previous studies (Takeya et al., 2000; Uchida et al., 2016 b, 2020), we fit the normalized nucleation probability $P(t)$ curves of Figure 5 to

$$
P(t)=1-\exp \left[-J\left(t-\tau_{0}\right)\right]
$$


TABLE 2 | Nucleation probability parameters (Equation 1).

\begin{tabular}{lccc}
\hline Sample & $\boldsymbol{\tau}_{\mathbf{0}}[\mathbf{h}]$ & $\boldsymbol{J}\left[\times \mathbf{1 0} \mathbf{0}^{-\mathbf{2}} \mathbf{h}^{-\mathbf{1}}\right]$ & $\left\langle\boldsymbol{\Delta} \boldsymbol{t}_{\text {ind }}>[\mathbf{h}]\right.$ \\
\hline $\mathrm{C}_{3} \mathrm{H}_{8}$-UFB-included water & -1.8 & $7.78 \pm 1.09$ & 14.1 \\
$\mathrm{C}_{3} \mathrm{H}_{8}$-hydrate dissociated water & -5.9 & $4.48 \pm 1.00$ & 16.9 \\
Pure water & -4.2 & $2.03 \pm 0.41$ & - \\
\hline
\end{tabular}

where $J$ is the nucleation rate and $\tau_{0}$ the offset time. Table 2 shows the resulting fits. The resulting values of $\tau_{0}$ are small and negative, indicating that most of the nucleation occurs at an early stage compared to other long induction times. The fits in Table 2 also show that the nucleation rate $J$ is larger in both $\mathrm{C}_{3} \mathrm{H}_{8}$-hydrate dissociated water and UFB-included water than that in pure water. However, compared to the rate increase by factors of 100 and 110 for $\mathrm{C}_{2} \mathrm{H}_{6}$ hydrate (Uchida et al., 2016b), these increases are only factors of about 2.2 times and 3.8 times, respectively, compared to that with pure water.

To quantify the promoting effect, we estimate the expected induction time $<\Delta t_{\text {ind }}>$ following the method of Sowa and Maeda (2015) and Uchida et al. (2016b). We compare the difference of areas below the nucleation probability curves between the test water and pure water (Figure 5). The resulting values give the magnitude on the promoting effect of $\mathrm{C}_{3} \mathrm{H}_{8}$ hydrate dissociated water and $\mathrm{C}_{3} \mathrm{H}_{8}$-UFB-included water. As shown in the last column of Table 2 , these two aqueous solutions have nearly the same value, which is consistent with the results obtained for $\mathrm{C}_{2} \mathrm{H}_{6}$ hydrate (Uchida et al., 2016b). The reason why the data and the curve do not fit well is considered to be mainly the small number of data. The additional number of experiments under the same condition would provide better solution in the future studies.

The above comparisons show that the UFBs exhibit the memory effect in $\mathrm{C}_{3} \mathrm{H}_{8}$ hydrate. Given that the nucleation of $\mathrm{C}_{3} \mathrm{H}_{8}$ hydrate is much more difficult than those of other gases, the exhibition of a promoting effect can be significant. For example, for $\mathrm{C}_{2} \mathrm{H}_{6}$ hydrate, the time at which the nucleation probability reaches 1 is about $1.2 \mathrm{~h}$ in pure water (Uchida et al., 2016a) and about $0.7 \mathrm{~h}$ for $\mathrm{CO}_{2}$ hydrate (Uchida et al., 2020), whereas for $\mathrm{C}_{3} \mathrm{H}_{8}$ hydrate, the probability of formation was as low as 0.6 even for $50 \mathrm{~h}$. With the promoting effect of UFBs, the time for nucleation of $\mathrm{C}_{2} \mathrm{H}_{6}$ hydrate is shorter by only about $15 \mathrm{~min}$ (Uchida et al., 2016a), whereas for $\mathrm{C}_{3} \mathrm{H}_{8}$ hydrate the time was shorter by more than $20 \mathrm{~h}$. In this way, the use of UFB-containing water is a promising way to promote those gas hydrates that are difficult to nucleate.

\section{Roles of UFBs on the Promoting Effects of $\mathrm{C}_{3} \mathrm{H}_{8}$ Hydrates}

The stability measurements indicate that the UFBs remained in high concentration $\left(\sim 10^{8} \mathrm{~mL}^{-1}\right)$ even after $50 \mathrm{~h}$ and stored at room temperature, we argue that they have a role in the promotion effect on $\mathrm{C}_{3} \mathrm{H}_{8}$ hydrate.

As the nucleation of gas hydrates occurs preferentially at the gas-liquid interface (Sloan and Koh, 2007), the induction time should be shorter in water with a much larger interface area,

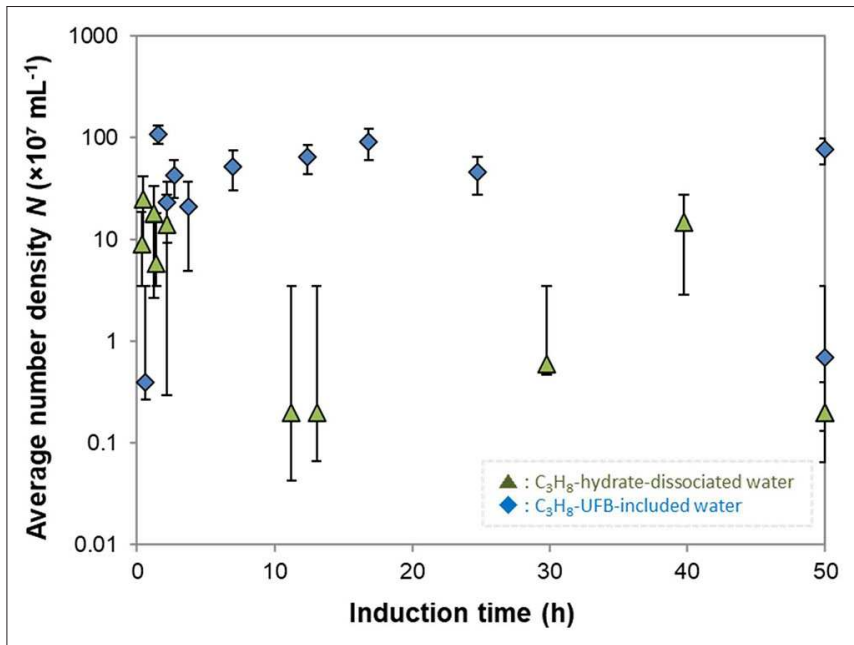

FIGURE 6 | Average number density of UFBs $N$ and induction times. Error bars show the standard deviation of measured number densities $(n>16)$.

that is, one containing many UFBs. The nucleation probability in Figure 5 shows that $\mathrm{C}_{3} \mathrm{H}_{8}$ hydrates are formed at a higher rate in the narrow $\Delta t$ range in the UFB-containing waters. This is associated with the increase of value of $J$. The increase of $J$ is also observed in other gas hydrate systems with UFBs (Uchida et al., 2016a, 2020). Thus, we assume that the gas-hydrate formation involves heterogeneous nucleation on the gas-liquid interface as argued previously.

To further investigate the roles of UFBs on hydrate formation, we measured the number density of UFBs in the aqueous solutions by the LS method prior to the formation experiments. Figure 6 shows the dependence of the induction time on the number density of larger UFBs ( $>300 \mathrm{~nm}$ ). This figure shows that the aqueous solutions contained UFBs with a number density $N$ of $10^{6}$ to $10^{9} \mathrm{~mL}^{-1}$. This figure also shows that the induction time does not clearly depend on $N$. This result suggests that the hydrate-formation process is not limited by the total area of the gas-liquid interface from the population of UFBs. Thus, the gasliquid interface appears crucial for nucleation, but its total area is not a key parameter. An explanation for this behavior was proposed by Lipenkov (2000) who suggested that the hydrate nucleation would preferentially occur at a certain size of bubble. In his investigation of air-hydrate distributions in the ice matrix retrieved from a deep ice sheet in Antarctica, he proposed a nucleation process in which air-hydrate crystals transformed from air bubbles smaller than a critical size. Testing this hypothesis requires both a greater number of hydrate formation tests under the same conditions and the actual size distribution of UFBs in each liquid sample over the diameter range from $10^{-9}$ to $10^{-5} \mathrm{~m}$. However, both of them are unfortunately difficult at present. As suggested by our results in Figure 3, it is still difficult to obtain the combined size distribution of UFBs obtained by FFT observations and by PTA measurements. Further quantitative investigations are needed. 


\section{CONCLUSION}

To help improve the technology for producing gas hydrate, we investigated the promoting mechanism for the memory effect on propane $\left(\mathrm{C}_{3} \mathrm{H}_{8}\right)$ hydrate. $\mathrm{C}_{3} \mathrm{H}_{8}$ is the main component of LPG, and an important component of natural gas, so its control technology is very important. However, $\mathrm{C}_{3} \mathrm{H}_{8}$ hydrate is difficult to form from pure water and pure $\mathrm{C}_{3} \mathrm{H}_{8}$ gas. This difficulty was reconfirmed in the present study. In particular, the nucleation probability within $50 \mathrm{~h}$ was about 0.6 , much lower than that found previously for ethane $\left(\mathrm{C}_{2} \mathrm{H}_{6}\right)$ hydrates. Therefore, the development of the formation-promotion technology on $\mathrm{C}_{3} \mathrm{H}_{8}$ hydrate is important.

We found that a key factor in the promoting effect is the presence of ultra-fine bubbles (UFBs). As had been found previously from dissociation of $\mathrm{CH}_{4}$ and $\mathrm{C}_{2} \mathrm{H}_{6}$ hydrates, the dissociation of $\mathrm{C}_{3} \mathrm{H}_{8}$-hydrate produced a similar amount of UFBs. Thus, UFBs have been found in both the dissociation of sI-type hydrates $\left(\mathrm{CH}_{4}\right.$ and $\left.\mathrm{C}_{2} \mathrm{H}_{6}\right)$ and sII-type hydrate $\left(\mathrm{C}_{3} \mathrm{H}_{8}\right)$. Concerning these UFBs, their number density tended to decrease with time, likely controlled by the saturation condition with guest gas in water. However, the fraction remaining within $50 \mathrm{~h}$ was at least 0.4 , with more than $10^{7} \mathrm{~mL}^{-1}$ remaining in water after $50 \mathrm{~h}$.

We compared the memory effect on $\mathrm{C}_{3} \mathrm{H}_{8}$ hydrates between two $\mathrm{C}_{3} \mathrm{H}_{8}$-UFB containing waters, specifically, $\mathrm{C}_{3} \mathrm{H}_{8}$-hydrate dissociated water and $\mathrm{C}_{3} \mathrm{H}_{8}$-UFB-included water prepared by an UFB generator. Based on 11 experiments with $\mathrm{C}_{3} \mathrm{H}_{8}$-hydrate formation, we found that the nucleation probability within $50 \mathrm{~h}$ was 1.3 times larger than that of the case with pure water, and that the induction time was shortened by nearly half. Therefore, we confirmed that UFB-containing water promoted the formation of $\mathrm{C}_{3} \mathrm{H}_{8}$ hydrates, with the two types of UFB-containing water giving nearly the same nucleation probability curve. We argued that this similarity does not support the idea that the promotion is due to a hydrate-memory structure in the water. In addition, we

\section{REFERENCES}

Bagherzadeh, S. A., Alavi, S., Ripmeester, J. A., and Englezos, P. (2015). Formation of methane nano-bubbles during hydrate decomposition and their effect on hydrate growth. J. Chem. Phys. 142:214701. doi: 10.1063/1.4920971

Buchanan, P., Soper, A. K., Thompson, H., Creek, J. L., Hubson, G., and Koh, C. A. (2005). Search for memory effects in methane hydrate: structure of water before hydrate formation and after hydrate decomposition. J. Chem. Phys. 123:164507. doi: $10.1063 / 1.2074927$

Christiansen, R. L., and Sloan, E. D. Jr. (1994). Mechanisms and kinetics of hydrate formation. Ann. NY Acad. Sci. 715, 283-305. doi: 10.1111/j.1749-6632.1994.tb38841.x

Giavarini, C., Maccioni, F., and Santarelli, M. L. (2003). Formation kinetics of propane hydrates. Ind. Eng. Chem. Res. 42, 1517-1521. doi: 10.1021/ie0207764

Gudmundsson, J., and Borrehaug, A. (1996). Frozen hydrate for transport of natural gas. Proc. ICGH 2, 415-422.

Horiguchi, K., Watanabe, S., Moriya, H., Nakai, S., Yoshimitsu, A., and Taoda, A. (2011). "Completion of natural gas hydrate (NGH) overland transportation demo project," in Proceedings of 7th International Conference (Edinburgh: Natural Gas Hydrates), 17-21.

Hwang, M. J., Wright, D. A., Kapur, A., and Holder, G. D. (1990). An experimental study of crystallization and crystal growth of methane hydrates found little correlation between the initial UFB number density and nucleation probability. Therefore, we argue that the memory effect of gas hydrates arises from the existence of guest-gas UFBs, which are mainly playing a role as the guest-gas supplying source, thus supporting the gas dissolution hypothesis.

\section{DATA AVAILABILITY STATEMENT}

The raw data supporting the conclusions of this article will be made available by the authors, without undue reservation.

\section{AUTHOR CONTRIBUTIONS}

TU, KY, and KG contributed conception and design of the study. AS performed the statistical analysis. TU wrote the first draft of the manuscript. TU, HM, and RS wrote sections of the manuscript. All authors contributed to manuscript revision, read and approved the submitted version.

\section{FUNDING}

This work was partly supported financially by the Tonen General Sekiyu Research/Development Encouragement \& Scholarship Foundation. The TEM observations were supported by the Hokkaido University Microstructure Characterization Platform's facility.

\section{ACKNOWLEDGMENTS}

The authors acknowledge the technical supports of TEM observations by Drs. N. Sakaguchi, and T. Tanioka (Hokkaido Univ.). PTA measurements were supported by Prof. K. Kimura, Mr. S. Kiuchi and Mr. H. Fernandes (Hokkaido Univ.). The authors also acknowledge the fruitful discussion in the Joint Research Program of the Institute of Low Temperature Science, Hokkaido University. from melting ice. J. Inclusion Phenom. Molecul. Recogn. Chem. 8, 103-116. doi: $10.1007 / \mathrm{BF} 01131291$

Ida, H., and Kohda, K. (2004). Highly Efficient Natural Gas Hydrate Production Technology. JFE Technical. Report No. 6, 76-80 (in Japanese with English abstract).

ISO 20408-1:2017. (2017). Fine Bubble Technology - General Principles for Usage and Measurement of Fine Bubbles - Part 1: Terminology . Available online at: https://www.iso.org/standard/68187.html?browse $\$=\$$ tc (accessed Febuary 27, 2020).

Kvenvolden, K. A. (1988). Methane hydrate - a major reservoir of carbon in the shallow geosphere? Chem. Geol. 71, 41-51. doi: 10.1016/0009-2541(88)90104-0

Lipenkov, V. Y. (2000). "Air bubbles and air-hydrate crystals in the vostok ice core," in Physics of Ice Core Records. ed T. Hondoh (Sapporo: Hokkaido Univ. Press), 327-358.

Masuda, Y., Uchida, T., Nagakubo, S., and Satoh, M. (2016). "Methane hydrates," in Fossil Fuels: Current Status and Future Directions, World Scientific Series in Current Energy Issues, ed G. M. Crawley (Singapore: World Scientific Pub. Co. Pte. Ltd.), 289-327. doi: 10.1142/9789814699983_0010

Mimachi, H., Takeya, S., Yoneyama, A., Hyodo, K., Takeda, T., Gotoh, Y., et al. (2014). Natural gas storage and transportation within gas hydrate of smaller particle: size dependence of self-preservation phenomenon of natural gas hydrate. Chem. Eng. Sci. 118, 208-213. doi: 10.1016/j.ces.2014.07.050 
Ohmura, R., Ogawa, M., Yasuoka, K., and Mori, Y. H. (2003). Statistical study of clathrate-hydrate nucleation in a water/hydrochlorofluorocarbon system: search for the nature of the "memory effect". J. Phys. Chem. B 107, 5289-5293. doi: $10.1021 /$ jp027094e

Oshita, S., and Uchida, T. (2013). "Basic Characterization of nanobubbles and its potential applications," in Bio-Nanotechnology: a Revolution in Biomedical Sciences, and Human Health. eds D. Bagchi, M. Bagchi, H. Moriyama, and F. Shahidi (West Sussex, UK: John Wiley and Sons, Ltd.), 506-516. doi: 10.1002/9781118451915.ch29

Parent, J. S., and Bishnoi, P. R. (1996). Investigation into the nucleation behavior of methane gas hydrates. Chem. Eng. Commun. 144, 51-64. doi: 10.1080/00986449608936444

Ripmeester, J. A., and Alavi, S. (2016). Some current challenges in clathrate hydrate science: nucleation, decomposition and the memory effect. Curr. Opin. Solid State Mater. Sci. 20, 344-351. doi: 10.1016/j.cossms.2016.03.005

Rodger, P. M. (2000). Methane hydrate, melting and memory. Ann. N.Y. Acad. Sci. 912, 474-482. doi: 10.1111/j.1749-6632.2000.tb06802.x

Seddon, J. R. T., Lohse, D., Ducker, W. A., and Craig, V. S. J. (2012). A deliberation on nanobubbles at surfaces and in bulk. ChemPhysChem 13, 2179-2187. doi: 10.1002/cphc.201100900

Sefidroodi, H., Abrahamsen, E., and Kelland, M. A. (2013). Investigation into the strength and source of the memory effect for cyclopentane hydrate. Chem. Eng. Sci. 87, 133-140. doi: 10.1016/j.ces.2012.10.018

Sloan, E. D. (2004). Fundamental principles and applications of natural gas hydrates. Nature 426, 353-363. doi: 10.1038/nature02135

Sloan, E. D., and Koh, C. A. (2007). Clathrate Hydrate of Natural Gases, 3rd Edn. Boca Raton, FL: CRC Press. doi: 10.1201/9781420008494

Sowa, B., and Maeda, N. (2015). Statistical study of the memory effect in model natural gas hydrate systems. J. Phys. Chem. A 119, 10784-10790. doi: $10.1021 /$ acs.jpca.5b07308

Takahashi, M. (2005). $\zeta$ potential of microbubbles in aqueous solutions: electrical properties of the gas-water interface. J. Phys. Chem. B 190, 21858-21864. doi: $10.1021 /$ jp0445270

Takeya, S., Hori, A., Hondoh, T., and Uchida, T. (2000). Freezing-memory effect of water on nucleation of CO2 hydrate crystals. J. Phys. Chem. B 104, 4164-4168. doi: 10.1021/jp993759+

Takeya, S., Mimachi, H., and Murayama, T. (2018). Methane storage in water frameworks: self-preservation of methane hydrate pellets formed from $\mathrm{NaCl}$ solutions. Appl. Energy 230, 86-93. doi: 10.1016/j.apenergy.2018. 08.015

The Chemical Society of Japan (2004). Kagaku-binran Handbook of Chemistry, 5th Edn. Tokyo: Maruzen Co. Ltd. 144-149.

Uchida, T., Liu, S., Enari, M., Oshita, S., Yamazaki, K., and Gohara, K. (2016c). Effect of $\mathrm{NaCl}$ on the lifetime of micro- and nanobubbles. Nanomaterials 6:31. doi: 10.3390/nano6020031

Uchida, T., Miyoshi, H., Yamazaki, K., and Gohara, K. (2020). "Effects of ultra-fine bubbles on exhibiting the memory effect," in Proceedings of 10th Interenational Conference (Singapore: Natural Gas Hydrates).

Uchida, T., Yamazaki, K., and Gohara, K. (2016a). Generation of micro- and nanobubbles in water by dissociation of gas hydrates. Korean J. Chem. Eng. 33, 1749-1755. doi: 10.1007/s11814-016-0032-7

Uchida, T., Yamazaki, K., and Gohara, K. (2016b). Gas nano-bubbles as nucleation acceleration in the gas-hydrate memory effect. J. Phys. Chem. C 120, 26620-26629. doi: 10.1021/acs.jpcc.6b07995

Uchida, T., Yamazaki, K., and Gohara, K. (2017). "Generation of gas nano-bubbles by gas hydrate dissociation and its effect on the memory effect," in Proceedings of 10th Interenational Conference (Denver, CL: Natural Gas Hydrates).

Yagasaki, T., Matsumoto, M., Andoh, Y., Okazaki, S., and Tanaka, H. (2014). Effect of bubble formation on the dissociation of methane hydrate in water: a molecular dynamic study. J. Phys. Chem. B 118, 1900-1906. doi: 10.1021/jp412692d

Zeng, H., Moudrakovski, I. L., Ripmeester, J. A., and Walker, V. K. (2006). Effect of antifreeze protein on nucleation, growth and memory of gas hydrates. AIChE J. 52, 3304-3309. doi: 10.1002/aic.10929

Conflict of Interest: The authors declare that the research was conducted in the absence of any commercial or financial relationships that could be construed as a potential conflict of interest.

Copyright (C) 2020 Uchida, Miyoshi, Sugibuchi, Suzuta, Yamazaki and Gohara. This is an open-access article distributed under the terms of the Creative Commons Attribution License (CC BY). The use, distribution or reproduction in other forums is permitted, provided the original author(s) and the copyright owner(s) are credited and that the original publication in this journal is cited, in accordance with accepted academic practice. No use, distribution or reproduction is permitted which does not comply with these terms. 


\section{NOMENCLATURE}

D

$J$

$N$

$\tau_{0}$

$<\Delta t_{\text {ind }}>$

$P(t)$

Average diameter of UFBs

Nucleation frequency

Number density of UFBs

Offset time

Expected induction time

Normalized nucleation probability by time $t$ 